\title{
Impact of intrauterine exposure to betamethasone on the testes and epididymides of prepubertal rats
}

\author{
Jorge Willian Franco de Barros, Cibele dos Santos Borges, Gabriela Missassi, \\ Tainá Louise Pacheco, Wilma De Grava Kempinas*
}

Department of Morphology, São Paulo State University (UNESP), Institute of Biosciences, Botucatu, SP, Brazil

\section{A R T I C L E I N F O}

\section{Keywords:}

Betamethasone

Pre-puberty

Male reproductive development

Rats

\begin{abstract}
A B S T R A C T
Therapy with betamethasone, a synthetic glucocorticoid, is used in cases of preterm birth risk, in order to promote fetal lung maturation, and decrease neonatal mortality and morbidity. However, late reproductive disorders related to the prenatal exposure to this compound have been reported by our Laboratory, in both male and female rats. Thus, the present study aimed to evaluate the impact of betamethasone on postnatal reproductive development, during pre-puberty, of male offspring exposed in utero to this synthetic glucocorticoid. For this purpose, pregnant Wistar rats were allocated into two groups: Control, treated with saline, and the group treated with betamethasone at $0.1 \mathrm{mg} / \mathrm{kg} /$ day. Control and betamethasone groups were treated with intramuscular injection on gestational days 12,13, 18 and 19, critical days of prenatal reproductive development. The treatment is associated with reduced body and organ weights, disorders in initial reproductive parameters of pre-pubertal male offspring exposed in utero to betamethasone, such as reduction of anogenital distance, alterations in histomorphometric parameters and immunostaining pattern of androgen and estrogen receptors on testicles and epididymides. Our results suggest that prenatal exposure to betamethasone potentially causes reproductive reprogramming and impairs male postnatal reproductive development. This data raise concerns about the use of betamethasone for human antenatal therapy.
\end{abstract}

\section{Introduction}

During mammalian development, many physiological factors, including hormones, are required to promote the appropriate maturation of the fetal tissues, organ and systems [1]. For example, in males reproductive development requires the action of sexual hormones such as testosterone, a steroid hormone synthesized mainly by the gonads $[2,3]$.

In rodents, the critical period of reproductive development that occurs between the gestational days (GD) 12 and 19 involves the differentiation of male gonad, with differentiation and proliferation of germ cells and immature Sertoli cells in the seminiferous tubules, and differentiation of Leydig cells in the interstitial tissue of the gonad [4]. The testosterone produced by the Leydig cells is responsible for the virilization of Wolffian duct, which differentiates into epididymis and vas deferens [2-4]. In the final days of this period also occurs the sexual differentiation of the nervous system, when a peak of testosterone promoted by the Leydig cells acts in the process of defeminization and masculinization of the hypothalamus, which leads to the typical male behavior pattern $[5,6]$.
Another class of steroid hormones involved in fetal development is the glucocorticoids, synthesized by the adrenal cortex, whose action mechanism is based on the modulation of genes expression [7]. Glucocorticoids play an important role during the gestational period, since these hormones act on the maturation of fetal tissues and such organs as the kidney, liver, brain and pituitary [8,9]. This hormone class is also responsible for the maturation of fetal lung, leading to the production of surfactant liquid before the birth $[8,10]$.

In the human clinics, the use of synthetic glucocorticoids, such as betamethasone, is of great relevance when there is any risk of preterm birth $[11,12]$, a problem that occurs in about $5-18 \%$ of pregnancies worldwide [13]. In this case, the glucocorticoids act in order to promote fetal lung maturation, which reduces the cases of neonatal mortality and morbidity [14].

However, recent studies conducted by our Laboratory reported that intrauterine exposure to this synthetic glucocorticoid is associated with reproductive disorders in rats during adulthood, in both male [15-17] and female [18] reproductive functions. Besides this, there are no studies on the impact on postnatal reproductive development of male offspring exposed in utero to betamethasone. Thus, this study aimed to

\footnotetext{
* Corresponding author. Rua Prof. Dr. Antônio Celso Wagner Zanin, 250, Departamento de Morfologia, Instituto de Biociências de Botucatu, Unesp, 18618-689, Botucatu, SP, Brazil.

E-mail addresses: wilma.kempinas@unesp.br, wilma.kempinas@pq.cnpq.br (W. De Grava Kempinas).
} 
evaluate the effects of prenatal exposure to betamethasone on the rat male postnatal reproductive development, during pre-puberty.

\section{Material and methods}

\subsection{Experimental design}

Adult male Wistar rats (90 days old, weighing approximately $300 \mathrm{~g}$ ) and adult female Wistar rats (70 days old, weighing approximately $200 \mathrm{~g}$ ) were obtained from the Multidisciplinary Center for Biological Investigation, State University of Campinas, and maintained under controlled conditions $(12 \mathrm{~h}$ of light $/ 12 \mathrm{~h}$ of darkness; average temperature of $23^{\circ} \mathrm{C}$ ), with food and water ad libitum. The animals were kept according to the Ethical Principles for Animal Experimentation, adopted by the Brazilian College of Animal Experimentation. The project was filed under number 451 with the Ethics Committee on Animal Experimentation of the UNESP Institute of Biosciences in Botucatu.

The mating of these animals in order to obtain pregnant females was performed during the dark period of the cycle, with two females being placed in the male cage. The initial day of pregnancy (Gestational day/ GD 0) was determined by the presence of spermatozoa in vaginal smears of estrus females. These were then kept in individual cages.

\subsection{Experimental groups and treatment}

Twelve pregnant females were allocated into two experimental groups: group treated with $0.1 \mathrm{mg} / \mathrm{kg} /$ day of betamethasone diluted in saline, and a control group treated with saline, both via intramuscular. This dose corresponds to the lowest human betamethasone clinical dose. The prenatal treatment was performed on GD 12 and 13, corresponding to the beginning of development of the rat reproductive system, and on GD 18 and 19, a critical period for sexual hypothalamic differentiation. The dose was adapted for rodents from human clinics $[16,19]$, based on the body surface area, as described by Reagan-Shaw et al. [20]. Betamethasone dose applied to human antenatal therapy is about $24 \mathrm{mg}$, divided into two equal doses in a $24 \mathrm{~h}$ interval [19]. In this study, the doses were divided again, in order to cover the critical window of prenatal reproductive development of rats.

\subsection{Anogenital distance}

In order to evaluate the initial sexual development in the males of each litter, after weighing, the distance between the genital papilla and the anus was recorded (anogenital distance - AGD) in the PND (postnatal day) 1. Since AGD can be influenced by factors other than treatment such as an exogenous agent, its measurement will be normalized to avoid them, being measured by the ratio between AGD and the cubic root of body weight [21].

\subsection{Male reproductive development}

The male offspring exposed in utero to betamethasone had their initial reproductive parameters evaluated at the ages of 7, 14 and 28 days, and compared to those obtained from the control group. At these times, one male per litter was initially weighed and then euthanized by decapitation. Thus, the lungs and adrenals of these animals were removed and weighed. Testicle and epididymis weights of 14 and 28 day old animals were also recorded. Testicles and epididymides of animals at PND 7 were not weighed because of their small size and delicate aspect, which could cause structural damage during their manipulation.

Briefly, these ages were chosen based on the specific events that occur in testicles [22] and epididymides [23], represented by immature stages of each organ, with few differentiated cells, up to stages with more complex cell types observed during pre-puberty.

\subsubsection{Histological procedures}

Analyses were performed on the testicles of rats at PND 7, 14 and 28, and in the epididymides of rats at PND 7 and 28. Epididymides of rats at PND 14 were not considered for histological procedures because the organ remains in an undifferentiated stage, despite the appearance of halo cells, which are derived from the immune system [23,24]. The testes ( $n=4-5$ per group) were collected and the albuginea tunica was sectioned at the poles with the aid of a small surgical scissors. These were then immersed in Bouin's fixative solution, as described by Russell et al. [25]. These materials were subsequently histologically processed, included in Paraplast, cut at a thickness of $5 \mu \mathrm{m}$ and stained with hematoxylin and eosin (HE).

For the histopathological evaluation, 100 seminiferous tubules were analyzed, from the three ages mentioned above, divided into three sections, in which the appearance of the epithelium, lumen content and interstitium were observed, in order to classify possible morphological lesions of these organs according to guidelines for toxicological studies $[22,26]$. Tubules were considered abnormal when acidophilic cells, multinucleated cells, tubular degeneration, vacuolization of the epithelium, germ cell depletion or exfoliation of cells into the lumen of the tubule was observed. The histopathological evaluation of the epididymis was performed on the animals aged 7 and 28 days. The appearance of the epithelium, the lumen content and the interstitium were qualitatively evaluated, also based on guidelines for toxicological studies [27].

We also evaluated the degree of maturation of the seminiferous epithelium, which was established through the analysis of 100 seminiferous tubules per animal at 28 days of age, chosen at random. For this purpose, we assigned values, based on the mature cell population of higher frequency in the tubular epithelium: grade 1 (primary or secondary spermatocytes); grade 2 (young spermatids and with rounded nuclei, in the 1-8 stages of spermiogenesis). The number of seminiferous tubules in each of the degrees was multiplied by the value of grade. The values obtained were summed and then divided by 100 , resulting in the average degree of maturation [28]. Moreover, 100 seminiferous tubules per animal were evaluated for the presence or absence of lumen, a histologic indication of reproductive development [22].

\subsubsection{Morphometric evaluations}

To evaluate the diameter of the seminiferous tubules, ten sections of seminiferous tubules were evaluated per animal from the control group and treated with betamethasone at the three ages mentioned above. For this purpose, a Leica DMLB microscope was used at $400 \times$ magnification with the software Leica Q-win (version 3) coupled with ImageJ $1.48 \mathrm{v}[16,29]$.

Sertoli cell nuclei were counted in histological sections of the testis in 20 seminiferous tubules per animal. This technique was used to predict the proliferative activity of Sertoli cells [16]. Furthermore, Sertoli cell may be indicative of germ cell population size in adult testis [30].

Leydig cell nuclear volume has been considered a sensitive indicator of the level of its secretory activity [31]. For Leydig cell karyometry, 50 nuclei were chosen randomly in either circular or elliptical form and their volume was obtained using the image analysis software Leica Qwin (version 3) with the aid of the software ImageJ 1.48. The nuclear volume of the Leydig cells was determined by the mathematical formula: [Diameter ${ }^{3} \times \pi \times \frac{1}{6}$ ].

\subsubsection{Immunohistochemistry for androgen receptors}

Immunohistochemistry assay for AR (Androgen receptors) was performed as described by Leite et al. [29], with modifications. Initially, the testes of the animals at 7, 14 and 28 days of age and the epididymides of the animals at 7 and 28 days of age were sectioned at a thickness of $5 \mu \mathrm{m}$ and placed on silanized slides. Next, the sections were dewaxed with xylol, hydrated with decreasing concentrations of 
A

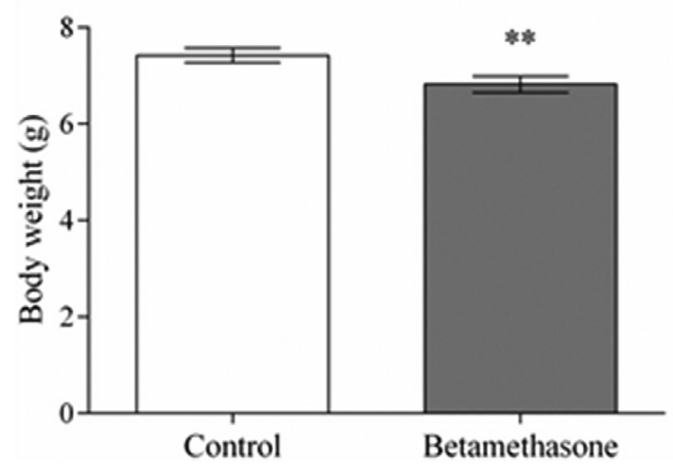

B

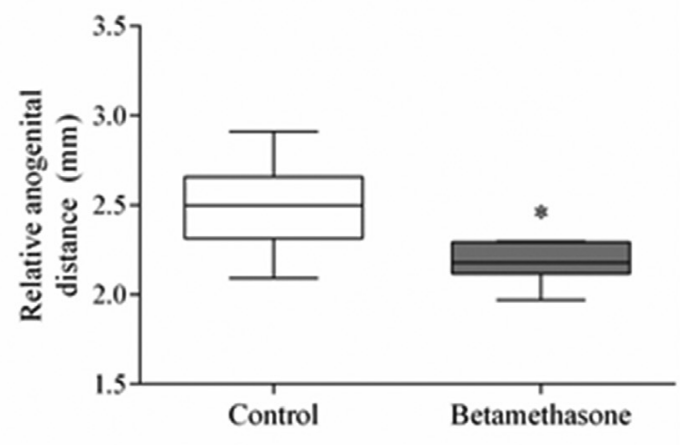

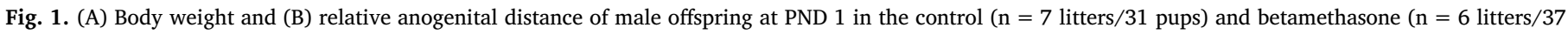
pups) groups. Values expressed as mean \pm S.E.M. (Student's $t$-test). ${ }^{*} \mathrm{p}<0.05 ;{ }^{* *} \mathrm{p}<0.01$.

alcohol, and washed with phosphate buffered saline (PBS - pH 7.4). Antigenic recovery was performed with citrate buffer $(\mathrm{pH} 6.0)$ for $40 \mathrm{~min}$ in a pressure cooker. After this step, the sections were incubated for $30 \mathrm{~min}$ with hydrogen peroxide (3\%) and methanol, in order to block the endogenous peroxidase. In the next step, the sections were incubated for $1 \mathrm{~h}$ with Bovine serum albumin (BSA 3\%) diluted in PBS, and then washed with PBS to be incubated overnight with the primary antibody anti-androgen receptor (AR N-20: sc-816, 1:100, Santa Cruz Biotechnology, CA, USA). After the incubation period, the sections were washed again with PBS and incubated for $2 \mathrm{~h}$ with the secondary antibody (Biotinylated Goat Anti-Rabbit Immunoglobulins, 1:100 - Vector Laboratories , CA, USA). Again the sections were washed with PBS and then incubated for $2 \mathrm{~h}$ with avidin-biotin-peroxidase solution (Vectastain Standard ABC Kit - Vector Laboratories ${ }^{\circ}$ CA, USA). Then, after further washing with PBS, the cuts were submitted, for $01 \mathrm{~min}$ and $30 \mathrm{~s}$, to the diaminobenzidine (DAB) associated with hydrogen peroxide. After the reaction was completed, the sections were washed with water and counterstained with hematoxylin. At the end of the procedure, the sections were dehydrated with increasing concentrations of alcohol and then immersed in xylol. The sections were covered with coverslips and analyzed under a Leica light microscope, coupled to a digital camera and a computer containing the software Leica Q-win (version 3).

\subsubsection{Immunohistochemistry for estrogen receptors $\alpha$-type}

Immunohistochemistry assay for ER- $\alpha$ (Estrogen Receptors $\alpha$-type) was performed based on Guerra et al. [32], with modifications. Initially, the testes of the animals at 7, 14 and 28 days of age and the epididymides of the animals at 7 and 28 days of age were sectioned at a thickness of $5 \mu \mathrm{m}$ and placed on silanized slides. Then, the sections were dewaxed with xylol, hydrated with decreasing concentrations of alcohol, and washed with phosphate buffered saline (PBS - pH 7.4). Antigenic recovery was performed with citrate buffer ( $\mathrm{pH}$ 6.0) for $55 \mathrm{~min}$ in a $37^{\circ} \mathrm{C}$ incubator. After this step, the sections were incubated for 30 min with hydrogen peroxide $(3.5 \%)$ and methanol, in order to block the endogenous peroxidase. In the next step, the sections were incubated for $1 \mathrm{~h}$ with Bovine Serum Albumin (BSA 3\%) diluted in PBS, and then washed with PBS to be incubated overnight with the primary antibody anti-estrogen receptor $\alpha$-type (ER $\alpha$ HC-20: sc-56836, 1:100, Santa Cruz Biotechnology, CA, USA). After the incubation period, the sections were washed again with PBS and incubated for $2 \mathrm{~h}$ with the secondary antibody (Biotinylated Horse Anti-Mouse Immunoglobulins, 1:100 - Vector Laboratories ${ }^{\varpi}, \mathrm{CA}$, USA). Again the sections were washed with PBS and then incubated for $2 \mathrm{~h}$ in avidin-biotin-peroxidase solution (Vectastain Standard ABC Kit - Vector Laboratories ${ }^{\circ}$ CA, USA). Then, after further washing with PBS, the cuts were submitted, for $08 \mathrm{~min}$, to the diaminobenzidine (DAB) associated with hydrogen peroxide. After the reaction, the sections were washed with water and counterstained with hematoxylin. At the end of the procedure, the sections were dehydrated with increasing concentrations of alcohol and then immersed in xylol. The sections were covered with coverslips and analyzed under a Leica light microscope, coupled to a digital camera and a computer containing the software Leica Q-win (version 3).

\subsection{Immunostaining evaluation}

In order to evaluate semi-quantitatively the testicular immunostaining pattern, 50 seminiferous tubules per animal were randomly assessed. The evaluation of the cell's immunostaining intensity was classified as "absent", "weak", "moderate" or "strong", and always compared with controls, as described by Petrusz et al. [33]. Interstitial tissue of testicles was also evaluated qualitatively. Based on Leite et al. [29], the immunostaining pattern in/of epithelial and interstitial cells of the epididymis was also qualitatively evaluated.

\subsection{Statistical analysis}

Data are presented as mean \pm standard error of mean (SEM), median and interquartile range or percentage. The results were analyzed by the Student's $t$-test, by the non-parametric Mann Whitney test or by the Chi-square test. The differences were considered statistically significant when $\mathrm{p} \leq 0.05$. Statistical analyses were performed using the software GraphPadPrism (version 5).

\section{Results}

Initial analysis at PND 1 revealed that males exposed in utero to betamethasone had lower body weights and lower AGD values (Fig. 1).

Decreased body weights were also reported at PND 14 and 28. In addition, at PND 14, the weights of the testes and epididymides were also decreased, compared to the control group. In relation to vital organs, there was no significant difference in the lung weight between groups. However, the absolute weight of the adrenal gland was significantly decreased at PND 14. Calculation of the relative weights to body weights revealed that the weight of the adrenal was decreased at PND 14 and increased at PND 28 (Table 1).

Histopathological evaluations of the testicles and epididymides did not differ between groups. Also, no variations were observed in the degree of maturation of the seminiferous epithelium. On the other hand, rats at PND 14 and 28 presented seminiferous tubules with smaller diameters. Lower numbers of Sertoli cells were also observed at these ages. In addition, the nuclear volume of Leydig cells was also reduced at PND 7, 14 and 28 (Table 2). Fig. 2 illustrates the histological aspect of the testicles and epididymides observed in the control and treated groups, at the different ages analyzed.

The evaluation of androgenic receptor by immunohistochemical assays revealed a reduction in the immunostaining pattern in the 
Table 1

Body and organ weights.

\begin{tabular}{|c|c|c|c|c|c|c|}
\hline \multirow[t]{3}{*}{ Parameter } & \multicolumn{6}{|l|}{ Group } \\
\hline & \multicolumn{2}{|l|}{ PND 7} & \multicolumn{2}{|l|}{ PND 14} & \multicolumn{2}{|l|}{ PND 28} \\
\hline & Control $(\mathrm{n}=5)$ & Betamethasone $(\mathrm{n}=6)$ & Control $(n=5)$ & Betamethasone $(\mathrm{n}=6)$ & Control $(n=5)$ & Betamethasone $(n=6)$ \\
\hline Body weight (g) & $16.90 \pm 0.81$ & $16.00 \pm 0.84$ & $34.00 \pm 1.20$ & $28.93 \pm 1.54^{*}$ & $111.50 \pm 2.41$ & $100.10 \pm 3.59^{*}$ \\
\hline \multicolumn{7}{|l|}{ Reproductive organ } \\
\hline Testicle (mg) & d. n. c. & d. n. c. & $49.33 \pm 2.60$ & $36.67 \pm 2.32^{* *}$ & $463.60 \pm 19.96$ & $420.90 \pm 21.41$ \\
\hline Testicle (mg/100 g) & d. n. c. & d. n. c. & $1.48 \pm 0.13$ & $1.27 \pm 0.05$ & $4.16 \pm 0.12$ & $4.23 \pm 0.26$ \\
\hline Epididymis (mg) & d. n. c. & d. n. c. & $10.66 \pm 0.72$ & $7.86 \pm 0.62^{*}$ & $42.38 \pm 1.40$ & $39.18 \pm 1.93$ \\
\hline Epididymis (mg/100 g) & d. n. c. & d. n. c. & $0.32 \pm 0.02$ & $0.27 \pm 0.02$ & $0.38 \pm 0.01$ & $0.39 \pm 0.02$ \\
\hline \multicolumn{7}{|c|}{ Glucocorticoid related organ } \\
\hline Lung (mg) & $360.00 \pm 25.39$ & $361.40 \pm 14.90$ & $544.00 \pm 7.57$ & $482.00 \pm 28.45$ & $854.30 \pm 34.26$ & $802.70 \pm 38.22$ \\
\hline Lung (mg/100 g) & $21.53 \pm 1.93$ & $22.80 \pm 1.12$ & $16.14 \pm 0.68$ & $16.70 \pm 0.60$ & $7.68 \pm 0.35$ & $8.04 \pm 0.36$ \\
\hline Adrenal (mg) & $1.46 \pm 0.21$ & $1.85 \pm 0.11$ & $4.26 \pm 0.16$ & $3.14 \pm 0.16^{* * *}$ & $11.32 \pm 0.04$ & $11.74 \pm 0.41$ \\
\hline Adrenal (mg/100 g) & $0.09 \pm 0.01$ & $0.12 \pm 0.004$ & $0.13 \pm 0.001$ & $0.11 \pm 0.01 *$ & $0.10 \pm 0.002$ & $0.12 \pm 0.01 *$ \\
\hline
\end{tabular}

Values expressed as mean \pm S.E.M (Student's $t$-test). ${ }^{*} \mathrm{p}<0.05 ;{ }^{* *} \mathrm{p}<0.01 ; * * * \mathrm{p}<0.001$. d. n. c. (Data not collected).

testicles of betamethasone-exposed rats at PND 7 and 28 (Table 3/ Fig. 3) and in the epididymis at PND 28 (Fig. 3). At PND 7, betamethasone group animals presented a higher percentage of seminiferous tubules with absence of immunostaining, but at PND 28 showed fewer tubules with strong immunostaining pattern in comparison with control.

In addition, the immunohistochemistry assay for type- $\alpha$ estrogen receptors also showed reduced immunostaining pattern in the testicles of animals treated with betamethasone (Table 3/Fig. 4). At PND 14, seminiferous tubules of betamethasone animals exhibited a lower percentage of strong immunostaining when compared with the control group. Furthermore, at PND 28, despite no statistical difference $(p=0.0556)$, the betamethasone group presented a higher percentage of seminiferous tubules with a moderate pattern of immunostaining and lower percentage of strong immunostaining in comparison with the control group.

\section{Discussion}

Several studies have reported that intrauterine exposure to synthetic glucocorticoids is related to the establishment of postnatal disorders in the body, events related to conceptions of fetal reprogramming. This subclass of steroid hormones is one of the major forces responsible for the modulation of metabolic, cardiovascular, immune and behavioral processes [10].

Due to their metabolic action, glucocorticoids are able to regulate the metabolism of carbohydrates, of lipids and proteins $[7,8]$. We observed that the male offspring exposed in utero to betamethasone had reduced body weight when compared to the control group. These data corroborate those obtained by Borges et al. [15,16], and may be indicative of environment adversity during development which leads to fetal reprogramming $[8,9]$.

In the present study we evaluated the weights of the lung and adrenal gland, both organs associated with glucocorticoids, either as the organ of action or organ of synthesis, respectively. We did not observe significant variations in lung weights between groups at different ages. However, the adrenal gland showed a significant decrease in weight at PND 14 in the treated group. The hypothalamic-pituitaryadrenal axis is negatively regulated by the increase of glucocorticoids in the bloodstream [7-9]. Thus, intrauterine exposure to betamethasone may have led to a suppressive effect on adrenal weight of the offspring [19] at PND 14, but by some compensatory mechanism this effect was no longer present at PND 28.

Studies in rodents show that both the treatment of pregnant females with glucocorticoids and the increase of corticosteroids generated by stress during the gestational period led to the passage of these hormones into the fetal circulation and consequently depressed the hypothalamic-pituitary-gonadal axis, promoting fall in the synthesis of testosterone [34,35]. In males, the initial testosterone peaks occur during gestational days 18 and 19 and repeat in the first hours after birth [6]. Thus, the process of defeminization occurs followed by the neural, morphological, behavioral and reproductive masculinization of the animal [5]. However, with the action of glucocorticoids on androgen synthesis, these processes might be disturbed [36]. In the present work males exposed in utero to betamethasone presented reduced relative AGD values, which indicates a failure in the defeminization process [37].

Postnatal days 7, 14 and 28 correspond to three different periods of postnatal reproductive development of pre-pubertal rats. At PND 7, the testicles are in the neonatal stage [22], presenting in their seminiferous

Table 2

Histologic and morphometric evaluation of the testicles.

\begin{tabular}{|c|c|c|c|c|c|c|}
\hline \multirow[t]{3}{*}{ Parameter } & \multicolumn{6}{|l|}{ Group } \\
\hline & \multicolumn{2}{|l|}{ PND 7} & \multicolumn{2}{|l|}{ PND 14} & \multicolumn{2}{|l|}{ PND 28} \\
\hline & Control $(n=5)$ & Betamethasone $(\mathrm{n}=5)$ & Control $(n=5)$ & Betamethasone $(n=5)$ & Control $(n=6-5)$ & Betamethasone $(n=4-5)$ \\
\hline${ }^{a}$ Normal seminiferous tubules (\%) & $96.0(94.0-98.0)$ & $93.0(91.0-96.5)$ & $78.0(72.5-82.5)$ & $77.0(73.5-79.0)$ & $75.0(71.2-80.0)$ & $80.0(69.0-83.5)$ \\
\hline${ }^{\mathrm{b}}$ Tubular diameter $(\mu \mathrm{m})$ & $58.47 \pm 0.50$ & $60.14 \pm 0.97$ & $82.95 \pm 1.05$ & $74.76 \pm 1.50^{* *}$ & $167.10 \pm 1.60$ & $159.90 \pm 1.02^{*}$ \\
\hline${ }^{\mathrm{b}}$ Sertoli cell count & $30.27 \pm 0.47$ & $29.17 \pm 0.95$ & $42.01 \pm 0.57$ & $37.73 \pm 0.41^{* *}$ & $33.66 \pm 0.62$ & $29.41 \pm 0.92^{* *}$ \\
\hline${ }^{\mathrm{b}}$ Leydig cell nuclear volume $\left(\mu \mathrm{m}^{3}\right)$ & $49.33 \pm 1.63$ & $42.32 \pm 0.73^{* *}$ & $63.88 \pm 2.74$ & $43.63 \pm 3.39^{* *}$ & $87.80 \pm 1.45$ & $80.79 \pm 2.37^{*}$ \\
\hline${ }^{a}$ Maturation degree of cells & d. n. c. & d. n. c. & d. n. c. & d. n. c. & $1.45(1.40-1.51)$ & $1.39(1.29-1.48)$ \\
\hline${ }^{a}$ Seminiferous tubules with lumen (\%) & d. n. c. & d. n. c. & d. n. c. & d. n. c. & $73.5(58.8-80.5)$ & $72.0(61.0-82.5)$ \\
\hline
\end{tabular}

*p $<0.05 ; *$ p $<0.01$. d. n. c. (Data not collected).

a Values expressed as median and interquartile range (Mann-Whitney test).

b Values expressed as mean \pm S.E.M. (Student's $t$-test). 


\section{Control Betamethasone}

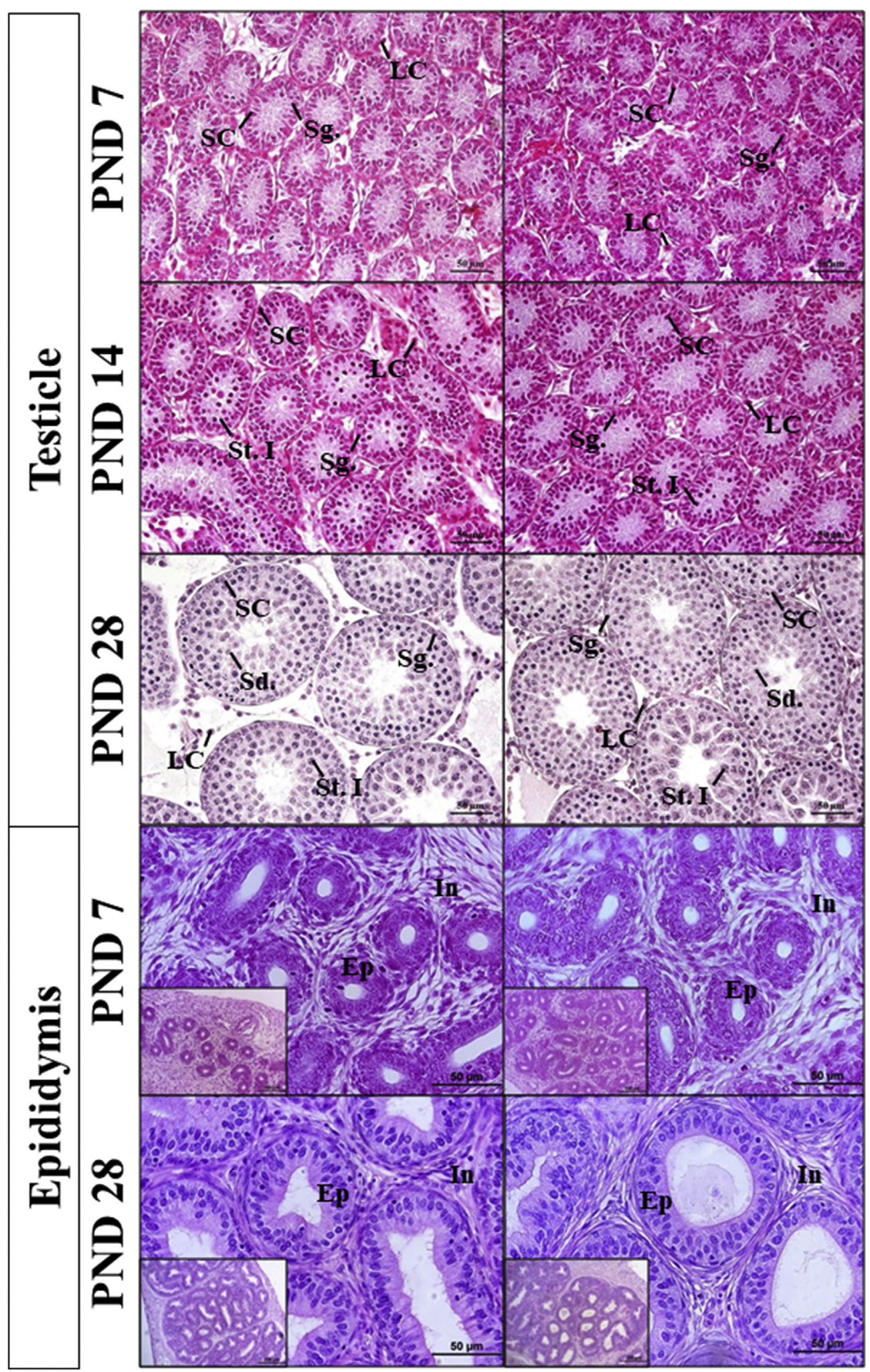

Fig. 2. Representative histological testicular and epididymal aspect of control and betamethasone-treated groups, at PND 7, 14 and 28 (Testicle), and PND 7 and 28 (Epididymis). SC (Sertoli cell), Sg. (Spermatogonia), LC (Leydig cell), St. I (Primary Spermatocyte), Sd. (Spermatid), Ep (Epididymal epithelium), In (Interstitial tissue). $100 \times, 200 \times$ and $400 \times$ magnification. 
Table 3

Semi-quantitative evaluation of immunostaining for Androgen and $\alpha$-type Estrogen receptors in the testicles.

\begin{tabular}{|c|c|c|c|c|c|c|}
\hline \multirow[t]{3}{*}{ Parameter } & \multicolumn{6}{|l|}{ Group } \\
\hline & \multicolumn{2}{|l|}{ PND 7} & \multicolumn{2}{|l|}{ PND 14} & \multicolumn{2}{|l|}{ PND 28} \\
\hline & Control $(n=4)$ & Betamethasone $(n=5)$ & Control $(n=5)$ & Betamethasone $(n=5)$ & Control $(n=5)$ & Betamethasone $(n=4-5)$ \\
\hline \multicolumn{7}{|c|}{ Androgen Receptors } \\
\hline \multicolumn{7}{|c|}{${ }^{a}$ Immunostaining on seminiferous tubules (\%) } \\
\hline Present & 93.0 & $78.0^{* * *}$ & 95.0 & 99.0 & 100.0 & 100.0 \\
\hline Absent & 7.0 & $22.0^{* * *}$ & 5.0 & 1.0 & 0.0 & 0.0 \\
\hline \multicolumn{7}{|c|}{ b Degree of immunostaning (\%) } \\
\hline Strong & $15.9(2.4-70.0)$ & $10.0(0.0-16.0)$ & $0.0(0.0-1.9)$ & $0.0(0.0-39.5)$ & $77.2(73.1-82.7)$ & $36.1(18.9-52.8)^{*}$ \\
\hline Moderate & $34.4(3.5-66.2)$ & $46.0(15.7-77.0)$ & $58.0(34.7-71.4)$ & $70.0(82.0-14.05)$ & $21.8(17.2-26.5)$ & $57.7(45.3-66.8)^{*}$ \\
\hline Weak & $21.6(2.0-62.8)$ & $10.0(3.0-50.3)$ & $34.6(27.5-57.2)$ & $23.5(2.7-64.0)$ & $0.0(0.0-1.5)$ & $0.0(0.0-19.2)$ \\
\hline \multicolumn{7}{|c|}{ Estrogen Receptors $\alpha$-type } \\
\hline \multicolumn{7}{|c|}{${ }^{a}$ Immunostaining on seminiferous tubules (\%) } \\
\hline Present & 100.0 & 100.0 & 100.0 & 100.0 & 100.0 & 100.0 \\
\hline Absent & 0.0 & 0.0 & 0.0 & 0.0 & 0.0 & 0.0 \\
\hline \multicolumn{7}{|c|}{${ }^{\mathrm{b}}$ Degree of immunostaning (\%) } \\
\hline Strong & $69.8(62.7-80.5)$ & $49.1(20.0-67.1)$ & $74.6(71.1-81.7)$ & $36.8(18.8-61.3)^{*}$ & $51.9(38.3-75.7)$ & $43.1(33.1-48.1)$ \\
\hline Moderate & $27.0(19.0-34.2)$ & $49.1(32.9-61.0)$ & $23.7(18.3-28.0)$ & $50.9(37.0-64.0)^{*}$ & $44.2(24.2-50.0)$ & $51.9(49.8-61.2)$ \\
\hline Weak & $0.9(0.0-5.6)$ & $1.8(0.0-18.9)$ & $0.0(0.0-1.7)$ & $3.5(1.6-21.5)$ & $3.8(0.0-11.6)$ & $4.0(0.0-8.3)$ \\
\hline
\end{tabular}

tubules rapidly proliferating Sertoli cells and gonocytes [38-40]. Fetal Leydig cells, present in the interstitium between the seminiferous tubules, go through the process of reversion and return to the stem cell state, which leads to a decrease in the synthesis of testosterone in the period between PND 6 and 30 [22]. In addition, the epididymis is in the undifferentiated period, due to its still undifferentiated epithelium and columnar cells $[23,41]$.

At PND 14, the testicles are in the infantile stage [22], in which the proliferation of Sertoli cells reduces and the blood-testis barrier begins to be formed. The first primary spermatocytes are already visible in the seminiferous tubules [22,38]. At this age, Leydig cells remain quiescent and present basal testosterone production [22]. Although we have not analyzed the epididymis at this age, the organ begins its phase of differentiation, marked by the appearance of halo cells, derived from the immune system [23,41].

At PND 28 the testicles are in the juvenile stage [22], in which the secondary spermatocytes originated by meiosis I and the rounded spermatids by meiosis II, can be visualized in the seminiferous tubules. The nuclei of the Sertoli cells are already located near the basal region of the seminiferous tubules, and with the spermatogonia, form a layer of cells in the tubular periphery [22,39,40]. Leydig cells remain in their basal state of testosterone synthesis; thus, germ cells in the seminiferous tubules that depend of the action of testosterone for their development, such as the primary spermatocytes during the pachytene phase, in meiosis I, undergo apoptosis $[22,40]$. In the same period, in the epididymis, columnar cells differentiate into principal cells, with structural functions, and basal cells, with a possible role in the electrolytic regulation of the principal cells $[23,41]$.

Although the histological aspect of the testes and epididymides did not differ between control and treated groups, morphometric analyses revealed a reduction in Leydig cell volume in the testes at PND 7, 14 and 28. Leydig cells in these three periods present discrete morphological variations and secretory function [39], being classified as fetal (up to PND 7) and immature Leydig cells (PND 8-32) [22,40]. Herein we do not provide the testosterone levels of the experimental animals; however, based on previous studies where rats were prenatally exposed to glucocorticoids, and had their testosterone levels reduced [16,35,37], we can infer that reduced nuclear volume of Leydig cells may indicate decreased androgen secretion.

As to the reduced androgenic activity, we found, by immunohistochemical assays, a reduction in the expression of androgen receptors in the testes at PND 7 and 28, as well as in the epididymis of the animals on PND 28. These findings corroborate prior reports in the literature of the inhibitory action of glucocorticoids on androgenic synthesis and action, which end up leading to impairment of male reproductive function. Illustrating such claims, the decline in androgenic synthesis or activity may, for example, lead to disorders in epididymal development, with implications for fertility in adult life [42].

The tubular diameter and number of Sertoli cells per seminiferous tubule were morphometric parameters that were also reduced in the animals at 14 and 28 days. At 14 days the Sertoli cell population is in proliferation within the seminiferous tubules, whose cell division rate decreases prior to the establishment of the blood-testis barrier, which occurs from PND 14, with the end of the divisions of these cells on PND 15 [22,38-40].

Borges et al. [15] observed that the rats exposed prenatally to betamethasone had lower numbers of spermatozoa during adult life. It is possible that reduction of Sertoli cell numbers per seminiferous tubule and reduction of tubular diameter restrict germ cell population proliferation [30], since Sertoli cells provide support to a limited number of cells of the spermatogenic lineage [43].

A reduction in the number of Sertoli cells may be associated with a reduction in estrogen biosynthesis or activity, since these hormones are related to the proliferation of these immature somatic cells $[44,45]$. The reduction in the expression of $\alpha$-type estrogen receptors in the testes of animals exposed to betamethasone, as evidenced by the immunohistochemical assay, may indicate a decrease in the action of estrogens on male gonadal development.

This experiment, performed in rodents during the gestational period, may be analogous to human first and second trimesters of pregnancy, but might not be an apt model to mimic the human context of antenatal betamethasone therapy that occurs at the third trimester of pregnancy [46]. However, the knowledge extracted from these studies may serve as a guide for understanding the effects of maternal stress on fetal reprogramming.

Despite the absence of data in the literature on reproductive outcomes in humans after antenatal therapy or prenatal glucocorticoid excess derived from maternal stress, several clinical studies report the effects of reprogrammed hypothalamus-pituitary-adrenal axis mediated by glucocorticoids on human physiology. In a review study conducted by Harris and Seckl [47], excess of glucocorticoid during gestation is associated with low birth weight and disorders of metabolism and 


\section{Control Betamethasone}

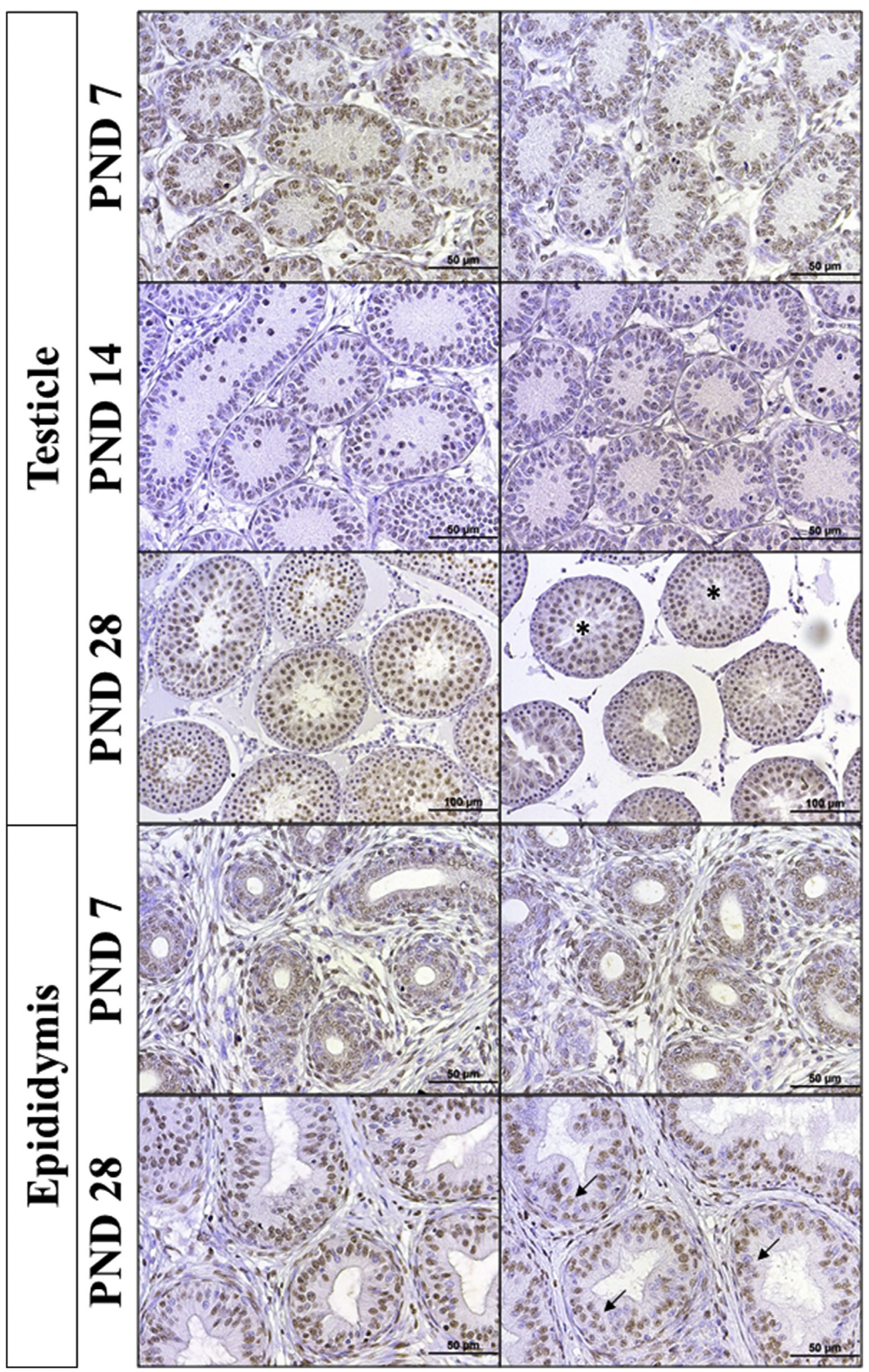

Fig. 3. Immunostaining for androgenic receptors (AR) in the testes of rats from the control and betamethasone groups on the postnatal days (PND) 7, 14 and 28 , and epididymides on the PND 7 and 28. Note the reduced intensity of immunostaining in the seminiferous tubules (asterisks) and epithelial cells of the epididymis (arrows) of the animals from the betamethasone group at PND $28.200 \times$ and $400 \times$ magnification. 


\section{Control Betamethasone}

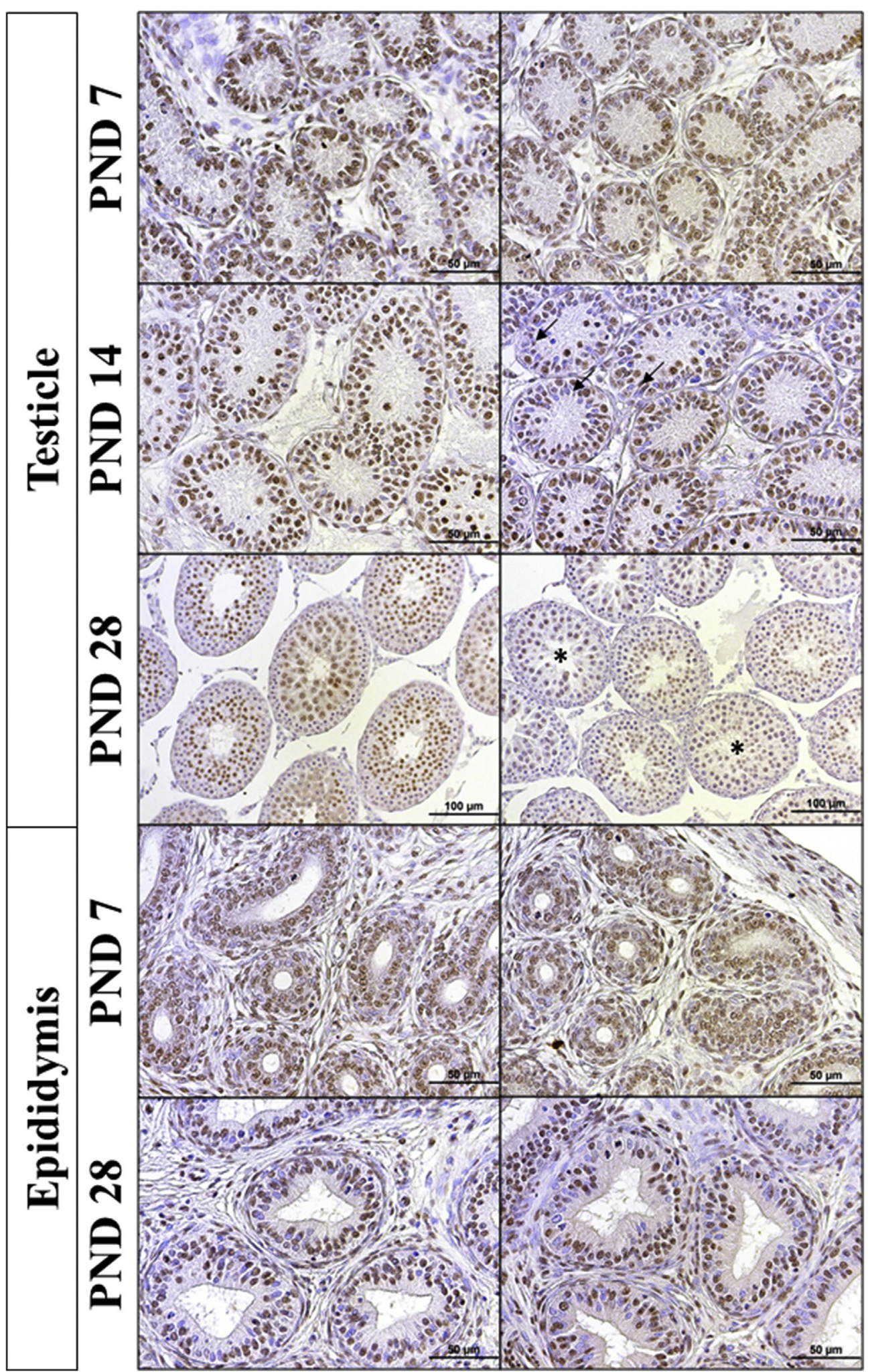

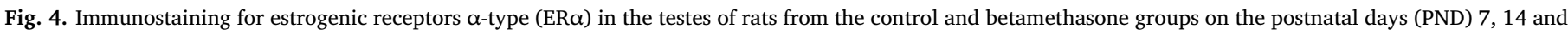

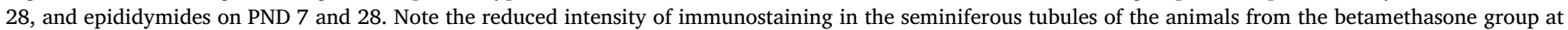
PND 14 (arrows) and 28 (asterisks). $200 \times$ and $400 \times$ magnification. 
neural functions of the offspring. Studies on glucocorticoid excess during gestation in other experimental models, such as farm animals, also indicate reprogramming effects, evidenced by disorders in metabolism and in the nervous and endocrine systems [8].

In conclusion, the results presented herein show that prenatal treatment with betamethasone provoked postnatal reproductive disorders, probably due to reproductive reprogramming caused by exposure to the glucocorticoid. Thus, more studies are encouraged, including other experimental models, in order to determine possible translational effects arising from the prenatal exposure to betamethasone and other synthetic glucocorticoids.

\section{Declaration of interest}

The authors declare that there is no conflict of interests.

\section{Acknowledgments}

The authors would like to acknowledge José Eduardo Bozano, from the Department of Morphology, Institute of Biosciences, São Paulo State University (UNESP). They are also grateful to São Paulo Research Foundation (FAPESP) [Grant numbers 2017/02764-9 and 2012/253501] and National Council for Scientific and Technological Development (CNPq) [Grant numbers 308842/2013-8 and 312118/2017-1].

\section{Transparency document}

Transparency document related to this article can be found online at http://dx.doi.org/10.1016/j.cbi.2018.06.030.

\section{References}

[1] R. Stark, R. Gibb, Hormones, Development, The Neurobiology of Brain and Behavioral Development, (2018), pp. 391-412, http://dx.doi.org/10.1016/B978-012-804036-2.00014-5 ch 14

[2] W.M. Haschek, C.G. Rousseaux, M.A. Walling, Male Reproductive System, Fundamentals of Toxicologic Pathology, 2nd Ed, (2010), pp. 553-597, http://dx. doi.org/10.1016/B978-0-12-370469-6.00018-0 ch 18.

[3] D.B. Joseph, C.M. Vezina, Male reproductive tract: development overview, Ref. Module Biomed. Sci. (2018), http://dx.doi.org/10.1016/B978-0-12-801238-3. 64366-0.

[4] T. Svingen, P. Koopman, Building the mammalian testis: origins, differentiation, and assembly of the component cell populations, Genes Dev. 27 (2013) 2409-2426, http://dx.doi.org/10.1101/gad.228080.113.

[5] I.L. Ward, Prenatal stress feminizes and demasculinizes the behavior of males, Science 175 (4017) (1972) 82-84, http://dx.doi.org/10.1126/science.175. 4017.82.

[6] I.L. Ward, J. Weisz, Differential effects of maternal stress on circulating levels of corticosterone, progesterone, and testosterone in male and female rat fetuses and their mothers, Endocrinology 114 (5) (1984) 1635-1644, http://dx.doi.org/10. 1210/endo-114-5-1635.

[7] J. Vandewalle, A. Luypaert, Therapeutic mechanisms of glucocorticoids, Trends Endocrinol. Metabol. 29 (1) (2018) 42-54, http://dx.doi.org/10.1016/j.tem.2017. 10.010 .

[8] A.L. Fowden, O.A. Valenzuela, O.R. Vaughan, J.K. Jellyman, A.J. Forhead, Glucocorticoid programming of intrauterine development, Domest. Anim. Endocrinol. 56 (2016) S121-S132, http://dx.doi.org/10.1016/j.domaniend.2016. 02.014 .

[9] B. Khulan, A.J. Drake, Glucocorticoids as mediators of developmental programming effects, Best Pract. Res. Clin. Endocrinol. Metabol. 26 (2012) 689-700, http://dx. doi.org/10.1016/j.beem.2012.03.007.

[10] P.P. Silveira, A.K. Portella, M.Z. Goldani, M.A. Barbieri, Developmental origins of health and disease (DOHaD), J. Pediatr. 83 (6) (2007) 494-504, http://dx.doi.org/ 10.2223/JPED 1728.

[11] P.A. Crowley, Antenatal corticosteroid therapy: a meta-analysis of the randomized trials, 1972 to 1994, Am. J. Obstet. Gynecol. 173 (1) (1995) 322-335, http://dx. doi.org/10.1016/0002-9378(95)90222-8.

[12] B.H. Lee, B.J. Stoll, S.A. McDonald, R.D. Higgins, Adverse neonatal outcomes associated with antenatal dexamethasone versus antenatal betamethasone, Pediatrics 117 (5) (2006) 1503-1510, http://dx.doi.org/10.1542/peds.2005-1749.

[13] S.E. Purisch, C. Gyamfi-Bannerman, Epidemiology of preterm birth, Semin. Perinatol. 41 (2017) 387-391, http://dx.doi.org/10.1053/j.semperi.2017.07.009.

[14] I. Gross, P.L. Ballard, Antenatal hormonal therapy for prevention of respiratory distress syndrome, Fetal and Neonatal Physiology, 5th Ed 1, 2017, pp. 825-830, , http://dx.doi.org/10.1016/B978-0-323-35214-7.00083-4 ch 83.

[15] C.S. Borges, A.F.M.G. Dias, P.V. Silva, J.L. Rosa, M.T. Guerra, R.F. Silva, L.R. Kiguti,
A.S. Pupo, W.G. Kempinas, Long-term adverse effects on reproductive function in male rats exposed prenatally to the glucocorticoid betamethasone, Toxicology 376 (2016) 15-22, http://dx.doi.org/10.1016/j.tox.2016.04.005.

[16] C.S. Borges, A.F.M.G. Dias, J.L. Rosa, P.V. Silva, R.F. Silva, A.L. Barros, M. Sanabria, M.T. Guerra, M. Gregory, D.G. Cyr, W.G. Kempinas, Alterations in male rats following in utero exposure to betamethasone suggests changes in reproductive programming, Reprod. Toxicol. 63 (2016) 125-134, http://dx.doi.org/10.1016/j. reprotox.2016.05.021.

[17] C.S. Borges, T.L. Pacheco, K.P. Silva, F.H. Fernandes, M. Gregory, A.S. Pupo, D.M.F. Salvadori, D.G. Cyr, W.G. Kempinas, Betamethasone causes intergenerational reproductive impairment in male rats, Reprod. Toxicol. 71 (2017) 108-117, http://dx.doi.org/10.1016/j.reprotox.2017.04.012.

[18] C.S. Borges, T.L. Pacheco, M.T. Guerra, A.L. Barros, P.V. Silva, G. Missassi, K.P. Silva, J.A. Anselmo-Franci, A.S. Pupo, W.G. Kempinas, Reproductive disorders in female rats after prenatal exposure to betamethasone, J. Appl. Toxicol. 37 (9) (2017) 1065-1072, http://dx.doi.org/10.1002/jat.3457.

[19] E. Souza, S. Kobayashi, M.J.S.L. Camano, L, Kulay Junior, Effect of betamethasone on pregnant rats: impact on corticosterone level and maternal and fetal adrenal glands, Rev. Bras. Ginecol. Obstet. 23 (10) (2001) 667-673, http://dx.doi.org/10 1590/S0100-72032001001000009.

[20] S. Reagan-Shaw, M. Nihal, N. Ahmed, Dose translation from animal to human studies revisited, Faseb. J. 22 (3) (2007) 659-661, http://dx.doi.org/10.1096/fj.07. 9574LSF.

[21] R.H. Gallavan Jr., J.F. Holson, D.G. Stump, J.F. Knapp, V.L. Reynolds, Interpreting the toxicologic significance of alterations in anogenital distance: potential for confounding effects of progeny body weights, Reprod. Toxicol. 13 (5) (1999) 383-390, http://dx.doi.org/10.1016/S0890-6238(99)00036-2.

[22] C.A. Picut, A.K. Remick, Impact of age on the male reproductive system from the Pathologist's perspective, Toxicol. Pathol. 45 (1) (2017) 195-205, http://dx.doi. org $/ 10.1177 / 0192623316672744$.

[23] B. Robaire, B.T. Hinton, The Epididymis: from Molecules to Clinical Practice: a Comprehensive Survey of the Efferent Ducts, the Epididymis and Vas Deferens, 1st Ed, (2002), p. 575, http://dx.doi.org/10.1007/978-1-4615-0679-9.

[24] B. Robaire, B.T. Hinton, The Epididymis, Knobil and Neill's Physiology of Reproduction, 4th Ed, (2015), pp. 691-771, http://dx.doi.org/10.1016/B978-0-12397175-3.00017-X ch 17.

[25] L.D. Russel, R.A. Ettlin, A.P.M. Hikim, E.D. Clegg, Histological and histopathological evaluation of the testis, Int. J. Androl. 16 (1) (1993) 83, http://dx.doi.org/10. 1111/j.1365-2605.1993.tb01156.x.

[26] G.L. Foley, Overview of male reproductive pathology, Toxicol. Pathol. 29 (1) (2001) 49-63, http://dx.doi.org/10.1080/019262301301418856.

[27] W.G. Kempinas, G.R. Klinefelter, Interpreting histopathology in the epididymis, Spermatogenesis 4 (2) (2014), http://dx.doi.org/10.4161/21565562.2014.979114 e979114-1-e979114-12.

[28] G.A.A. Leite, T.M. Figueiredo, M. Sanabria, A.F.M.G. Dias, P.V. Silva, A.D.C. Martins Junior, F. Barbosa Junior, W.G. Kempinas, Ascorbic acid supplementation partially prevents the delayed reproductive development in juvenile male rats exposed to rosuvastatin since prepuberty, Reprod. Toxicol. 73 (2017) 328-338, http://dx.doi org/10.1016/j.reprotox.2017.07.006.

[29] G.A.A. Leite, M. Sanabria, M.M. Cavariani, J.A. Anselmo-Franci, P.F.F. Pinheiro, R.F. Domeniconi, W.G. Kempinas, Lower sperm quality and testicular and epididymal structural impairment in adult rats exposed to rosuvastatin during prepuberty, J. Appl. Toxicol. 38 (6) (2018) 1-16, http://dx.doi.org/10.1002/jat.3599.

[30] D. Rebourcet, A. Darbey, A. Monteiro, U. Soffientini, Y.T. Tsai, I. Handel, J. Pitetti, S. Nef, L.B. Smith, P.J. O'Shaughnessy, Sertoli cell number defines and predicts germ and Leydig cell population sizes in the adult mouse testis, Endocrinology 158 (9) (2017) 2955-2969, http://dx.doi.org/10.1210/en.2017-00196.

[31] P. Fichna, L.K. Malendowicz, A karyometric and stereologic study of the effects of gonadotrophin and testosterone on the interstitial gland of the testis of intact and endoxan treated rats, Cell Tissue Res. 164 (3) (1975) 411-424, http://dx.doi.org/ 10.100/2FBF00223018.

[32] M.T. Guerra, M. Sanabria, G. Grossman, P. Petrusz, W.G. Kempinas, Excess androgen during perinatal life alters steroid receptor expression, apoptosis, and cell proliferation in the uteri of the offspring, Reprod. Toxicol. 40 (2013) 1-7, http://dx doi.org/10.1016/j.reprotox.2013.05.001.

[33] P. Petrusz, P. Dimeo, P. Ordronneau, C. Weaver, D.A. Keefer, Improved immunoglobulin-enzyme bridge method for light microscopic demonstration of hormone-containing cells of the rat adenohypophysis, Histochemistry 46 (1975) 9-26, http://dx.doi.org/10.1007/BF02463558.

[34] L.G. Dahlöf, E. Hard, K. Larsson, Sexual differentiation of offspring of mothers treated with cortisone during pregnancy, Physiol. Behav. 21 (4) (1978) 673-674, http://dx.doi.org/10.1016/0031-9384(78)90149-X.

[35] O.C.M. Pereira, A.C. Arena, F. Yasuhara, W.G. Kempinas, Effects of prenatal hydrocortisone acetate exposure on fertility and sexual behavior in male rats, Regul. Toxicol. Pharmacol. 38 (1) (2003) 36-42, http://dx.doi.org/10.1016/S02732300(03)00046-1.

[36] R.C. Piffer, P.C. Garcia, O.C.M. Pereira, Adult partner preference and sexual behavior of male rats exposed prenatally to betamethasone, Physiol. Behav. 98 (1-2) (2009) 163-167, http://dx.doi.org/10.1016/j.physbeh.2009.05.003.

[37] R.C. Piffer, P.C. Garcia, D.C. Gerardin, W.G. Kempinas, O.C.M. Pereira, Semen parameters, fertility and testosterone levels in male rats exposed prenatally to betamethasone, Reprod. Fertil. Dev. 21 (5) (2009) 634-639, http://dx.doi.org/10. 1071/RD08203.

[38] Y. Clermont, B. Perey, Quantitative study of the cell population of the seminiferous tubules in immature rats, Am. J. Anat. 100 (2) (1957) 241-267, http://dx.doi.org/ 10.1002/aja.1001000205. 
[39] B.P. Setchell, T. Hertel, O. Söder, Postnatal testicular development, cellular organization and paracrine regulation, the developing testis: physiology and pathophysiology, Endocr. Dev. 5 (2003) 24-37, http://dx.doi.org/10.1159/000069295.

[40] C.A. Picut, A.K. Remick, E.P. Rejik, M.L. Simons, D.G. Stump, G.A. Parker, Postnatal development of the testis in the rat: morphologic study and correlation of morphology to neuroendocrine parameters, Toxicol. Pathol. 45 (3) (2014) 326-342, http://dx.doi.org/10.1177/0192623314547279.

[41] K.F. Arrotéia, P.V. Garcia, M.F. Barbieri, M.L. Justino, L.A.V. Pereira, The Epididymis: Embryology, Structure, Function and its Role in Fertilization and Infertility, Embryology - Updates and Highlights on Classic Topics, (2012), pp. 41-66, http://dx.doi.org/10.5772/35847.

[42] W.G. Kempinas, G.R. Klinefelter, The Epididymis as a Target for Toxicants, Comprehensive Toxicology (Não tem), 3rd Ed, (2018), pp. 112-127 ch 4.06.

[43] W.E. Berndtson, T.L. Thompson, Changing relationships between testis size, Sertoli cell number and spermatogenesis in Sprague-Dawley rats, J. Androl. 11 (5) (1990) 429-435, http://dx.doi.org/10.1002/j.1939-4640.1990.tb00171.x.
[44] T.F. Lucas, E.R. Siu, C.A. Esteves, H.P. Monteiro, C.A. Oliveira, C.S. Porto, M.F. Lazari, 17 beta-estradiol induces the translocation of the estrogen receptors ESR1 and ESR2 to the cell membrane, MAPK3/1 phosphorylation and proliferation of cultured immature rat Sertoli cells, Biol. Reprod. 78 (1) (2008) 101-114, http:// dx.doi.org/10.1095/biolreprod.107.063909.

[45] P.S. Cooke, M.K. Nanjappa, C. Ko, G.S. Prins, R.A. Hess, Estrogens in male physiology, Physiol. Rev. 97 (2017) 995-1043, http://dx.doi.org/10.1152/physrev. 00018.2016.

[46] S. Whirledge, J.A. Cidlowski, Glucocorticoids and Reproduction: Traffic Control on the road to reproduction, Trends Endocrinol. Metabol. 28 (6) (2017) 399-415, http://dx.doi.org/10.1016/j.tem.2017.02.005.

[47] A. Harris, J. Seckl, Glucocorticoids, prenatal stress and the programming of disease, Horm. Behav. 59 (2011) 279-289, http://dx.doi.org/10.1016/j.yhbeh.2010.06. 007. 